\title{
SLIDING WEAR RESISTANCE OF BIOMORPHIC SiC CERAMICS
}

M. C. Vera ${ }^{1}$, J. Ramírez-Rico ${ }^{1 *}$, J. Martínez-Fernandez ${ }^{1}$, M. Singh ${ }^{2}$

${ }^{1}$ Dpto. Física de la Materia Condensada-ICMS, Universidad de Sevilla-CSIC, 41012 Sevilla, Spain.

${ }^{2}$ Ohio Aerospace Institute, Cleveland, $\mathrm{OH}$

\begin{abstract}
Biomorphic SiC ceramics were fabricated from four different wood precursors and their Knoop hardness and sliding wear resistance when sliding against a $\mathrm{Si}_{3} \mathrm{~N}_{4}$ ball in air were studied.

Tribological experiments were performed using a pin on disk apparatus, under normal loads of 2 and $5 \mathrm{~N}$, at a sliding speed of $100 \mathrm{~mm} / \mathrm{s}$. The effects of specimen porosity and microstructure on measured wear were evaluated. A commercial sintered silicon carbide ceramic was also tested for comparison. Small differences in friction coefficient comparable to monolithic SiC ceramics were obtained. Several concurrent wear mechanisms are taking place: microfracture, plastic deformation in the Si phase and oxidation of the Si and/or SiC phase. The presence of an oxide tribolayer was assessed using fluorescence microscopy. Wear rates were found to scale with $\mathrm{SiC}$ content and depend on residual porosity in the composite.
\end{abstract}

\section{Introduction}

Biomorphic Silicon Carbide (BioSiC) is a reaction formed silicon carbide material obtained from silicon melt infiltration of a porous carbon preform derived from wood or wood-related precursors though high temperature pyrolysis. The resulting material is a $\mathrm{SiC} / \mathrm{Si} \mathrm{composite}$ with a microstructure that mimics that of the original precursor [1-4], consisting of a porous SiC scaffold with hierarchical porosity elongated in the direction of the wood precursor growth, often filled totally or partially with residual silicon depending on the carbon scaffold's initial pore distribution [5]. This residual silicon can then be removed by chemical etching to obtain a porous silicon carbide scaffold with anisotropic porosity [6].

Processing of bioSiC involves three steps: first, a wood precursor is selected according to its density and pore size distribution, which is rough machined and then pyrolyzed in an inert atmosphere at temperatures in the range of $800^{\circ} \mathrm{C}$ to $1000^{\circ} \mathrm{C}$. A porous carbon material which conserves the original wood microstructure is thus obtained, which is then machined to near

\footnotetext{
*Corresponding author - Email: jrr@us.es, Tel: +34 954550936
} 
net shape and melt infiltrated in vacuum with excess silicon at temperatures in the range of $1450{ }^{\circ} \mathrm{C}$ to $1550{ }^{\circ} \mathrm{C}$. The infiltration step introduces no additional volume or shape changes, making this a near net-shape process and significantly reducing manufacturing costs over other silicon carbide materials that can only be produced in simple shapes.

An additional advantage of bioSiC stems from its anisotropic microstructure which optimizes properties along the direction of the channels in the original wood precursor (the direction of tree growth). This property, along with the presence of a hierchically interconnected porosity network optimized for fluid transport as well as compressive and bending strength has made bioSiC an interesting material in medical implants and prosthetics, specially in load-bearing bone substitution. BioSiC is non-cytotoxic and posesses favorable osteo-integration properties when coated with a bioactive glass [7-13], nanostructured elecrophoretic hydroxiapatite [14] and in-vitro precipitated HAP [15]. A hybrid prosthetic device containing an outer shell of porous bioSiC and an inner shell of hydroxyapatite/collagen was recently demonstrated to be safe and feasible, and showed enhanced bone-to-implant contact as well as new bone growth [16].

Many of the proposed applications for bioSiC are load-bearing, involve friction and sliding conditions or a combination of both. However, while mechanical properties such as strength, hardness and thoughness have been extensively evaluated [17-23], in the case of wear only erosion has been studied [24, 25], and no sliding wear studies exist in the literature to the best of our knowledge. With this in mind, we have studied sliding wear of bioSiC derived from wood precursors of different species at different applied loads, with the double intention of obtaining relevant data of friction coefficients and wear rates as well as to elucidate the effect of microstructure and, ultimately, wood precursor, on these properties.

\section{Materials and Methods}

SiC-based biomorphic ceramics were fabricated by reactive infiltration of carbonaceous preforms of pyrolyzed wood with molten silicon. Basic features of biomorphic SiC fabrication process have been described elsewhere [4, 19, 26-29]. For this study, wood specimens of Mahogany (Swietenia mahagoni), Sugar Pine (Pinus Lambertiana), Black Walnut (Juglans Nigra) and Maple (Acer Pseudoplatanus) were pyrolized in a flowing Ar atmosphere at temperatures in the range of $800^{\circ} \mathrm{C}$ to $1000^{\circ} \mathrm{C}$. The porous carbon performs obtained were machined to near net shape in cylinders $25.4 \mathrm{~mm}$ in diameter and melt infiltrated in vacuum with excess Si at 
$1460^{\circ} \mathrm{C}$ for 1 hour to obtain a siliconized silicon carbide material with a microstructure that mimics that of the original wood precursor.

Specimen for SEM observation were prepared by conventional metallographic techniques amd volume fractions of $\mathrm{Si}, \mathrm{SiC}$ and $\mathrm{C} /$ porosity were estimated using image analysis of at least ten micrographs for each type of specimens. Images were thresholded and the area fractions of each phase measured; due to the elongated nature of the microstructure, it is assumed that volume fractions can be extrapolated from area fractions. The results are included in Table 1 , along with the measured (geometrical) densities.

Knoop hardness tests were carried out with a microindenter under loads of 200 and 500 gf and $15 \mathrm{~s}$ indentation time. A total of 20 indentations were performed in randomly selected locations along each sample, for each load and material tested. Measurement of the indent size was carried out under an optical microscope.

Friction experiments were performed on a pin-on-disk tribometer consisting of stationary pin sliding on rotating disk. A ball on disk geometry was chosen to avoid misalignment problems. Sections of bioSiC material from different precursors were polished to the $\mathrm{R}_{\mathrm{a}}$ value included in Table 1 and used as disks. Hexoloy SiC (Hexoloy SA, Saint Gobain Ceramics, Niagara Falls, NY) and $300 \mu \mathrm{m}$ silicon wafers (Sigma Aldrich) were also tested as disks for comparison purposes. Commercially available $6 \mathrm{~mm}$ diameter $\mathrm{Si}_{3} \mathrm{~N}_{4}$ balls were used as counter surface. Both disks and balls were cleaned in acetone in an ultrasonic bath for 10 minutes and dried in air prior to use. Tests were carried out at a constant sliding speed of $100 \mathrm{~mm} / \mathrm{s}$ under two different normal loads, 5 and $2 \mathrm{~N}$, to evaluate the influence of the applied load on the friction coefficient. The normal loads were applied parallel to the direction of the channels in the original wood precursor, that is parallel to the wood growth axis (axial), along which these materials are typically harder $[23,30]$. The friction coefficient is the ratio $F / L$, were $F$ is the friction force measured with a precision of $0.01 \mathrm{~N}$ and $L$ the normal load. The tests were performed at ambient conditions (35-45 \% RH, RT) in air without lubrication.

Surface topography of the bioSiC specimens after those tribological tests was measured with with two different techniques, a contact profilometer and an interferometer microscope. As the cross section profile of a wear track cannot be assumed to be uniform, profile meter traces across each wear scar at four representative positions were obtained and averaged together. The volume of the worn out material was calculated by multiplying the averaged cross section 
area of the wear track times the length of the wear track. The specific wear rate is calculated as $k=V L^{-1} d^{-1}$, where $V$ is the volume of material worn, $L$ the normal load and $d$ the sliding distance. Wear rate of the $\mathrm{Si}_{3} \mathrm{~N}_{4}$ balls was calculated in the same way. The volume loss in this case was calculated by means of geometrical arguments after measuring the radius of the quasi-circular scars on the balls with an optical microscope.

Worn surfaces of the bioSiC material were characterized using scanning electron microscopy coupled with energy-dispersive X-ray spectrometry after cleaning them with compressed air. To evaluate the possible presence of an oxide tribo-film, an epifluorescence optical microscope using a $405 \mathrm{~nm}$ excitation wavelength laser source was used to record the fluorescence spectra emmited from the wear track region of the material. In order to be able to indentify the fluorescence signature, a commercial single-crystal Si wafer sample was used as a disk in ballon-disk experiments at the same experimental conditions as the bioSiC materials, and the fluorescence spectra from the wear track recorded for comparison.

\section{Results and Discussion}

\subsection{Microstructure and composition}

Figure 1 shows SEM micrographs of axial sections (perpendicular to the wood growth axis) of all types of bioSiC studied, obtained from four different precursors. It can be seen that the microstructure closely resembles that of the original wood precursor and consists of a continuous $\mathrm{SiC}$ scaffold with elongated channels which are completely (in the case of Maple and Sugar Pine) or partially (in the case of Mahogany and Black Walnut) filled with residual Si. Presence of hollow channels in bioSiC is determined by the channel size distribution in the wood precursor [5]. Some residual, unreacted carbon is also present in the material. Estimated volume fractions of $\mathrm{SiC}$ and unreacted $\mathrm{C}$ and $\mathrm{Si}$ phases are included in Table 1, together with average geometric density for the four types of samples studied. Due to the difficulty of distinguishing residual carbon from porosity using backscattered electrons in the SEM, both contributions are included together in the table. In the case of the commercial hexoloy $\mathrm{SiC}$ reference samples, significant porosity was observed (not shown) giving a $\mathrm{SiC}$ volume fraction of $94 \%$. Surface roughness of each specimen measured with a profilometer is also included in Table 1. The presence of hollow channels in black walnut-derived bioSiC precluded us from obtaining an accurate roughness value. 


\subsection{Knoop Hardness}

Measured Knoop hardness for all bioSiC materials studied and Hexoloy is plotted in Figure 2 as a function of $\mathrm{SiC}$ volume fraction, along with representative optical microscope images of the indentations. At the studied loads no cracks were observed to emanate from the indent's corners, and only a slight dependence with load was observed typical of an indentation size effect, although not enough load values were studied in this work to establish a trend. For a constant load value, Knoop hardness can be seen to increase with increasing SiC content in all cases (HK for silicon is 1150-1200 depending on orientation [31]). This result is different from what Gutierrez Mora et al. [23] observed in White Eucalyptus, Beech and Pine-derived bioSiC, where a decrease in Vickers hardness with increasing SiC content was attributed to plasticity effects in the Si phase. Due to much higher porosity values in their samples (20-30\%), they distinguished between two different regions of dense and porous material while in this work hardness was tested in random locations. It is likely that the actual hardness vs. SiC fraction dependence results from interplay between $\mathrm{SiC}$ and $\mathrm{Si}$ fractions as well as porosity and therefore a statistical treatment and possibly hardness mapping through nanoindentation would be required to fully elucidate this dependence. In the case of this work, however, the presented data is enough to establish a trend that will be useful in the analysis of wear rates below.

\subsection{Friction and wear}

Figure 3 show friction coefficient values of bioSiC materials and Hexoloy vs sliding distance when sliding against a $\mathrm{Si}_{3} \mathrm{~N}_{4}$ ball at a sliding speed of $100 \mathrm{~mm} / \mathrm{s}$ under 2 and $5 \mathrm{~N}$ normal load. All values of the friction coefficient fall in the range of $0.6-0.7$, which is in the range reported for hot-pressed and reaction bonded SiC under similar dry contact conditions [32-34], except for Black Walnut-derived bioSiC, which at $2 \mathrm{~N}$ load is $\sim 0.8$, possibly due to the presence of hollow pores and channels. The friction coefficient of silicon is also depicted, however in this case tests were aborted prematurely as the thin wafers failed after a sliding distance in the range of 200-250 m. A plot of friction coefficient averaged over the last $200 \mathrm{~m}$ of sliding vs. SiC content (as volume fraction) is included in Figure 4.

Figure 5 depicts measured wear rates for the $\mathrm{Si}_{3} \mathrm{~N}_{4}$ ball (top) and the bioSiC and Hexoloy disks (bottom) at the two tested loads. Wear rates in black-walnut derived SiC could not be measured due to the presence of hollow channels normal to the disk surface, which precluded us from obtaining clear surface profiles both using a contact profilometer or interferometric 
microscopy. In the rest of the materials studied, wear rates determined using the two techniques were equal within the experimental error. Wear rates are one to two orders of magnitude higher for bioSiC than for Hexoloy, and is highest for sugar pine-derived bioSiC, the material with the highest free Si content of all the samples studied. Moreover, although in all cases wear rates were higher at $5 \mathrm{~N}$ load as expected, this difference is most significant in the latest case, as wear of both the ball and the disk at $5 \mathrm{~N}$ is three to five times that at $2 \mathrm{~N}$. To elucidate the effect of $\mathrm{SiC}$ content of the wear rate, Figure 6 plots the measured wear rate vs. $\mathrm{SiC}$ volume fraction in all cases where wear rates could be determined. A clear trend can be observed where the wear rate diminishes with increasing SiC content.

\subsection{Wear mechanisms}

Several concurrent mechanisms are responsible for wear in $\mathrm{SiC}$ and $\mathrm{SiC}$-based materials, and their influence depends on the experimental conditions. In low Si content materials surface fracture, ploughing, plastic deformation and formation and removal of an oxide film have been shown to be responsible for wear in unlubricated $\mathrm{SiC}$ [32-34] and $\mathrm{Si}_{3} \mathrm{~N}_{4}$ [35]. Since bioSiC is a siliconized SiC ceramic, the effect of $\mathrm{Si}$ in the material is expected to have an impact on the wear rate, especially since both plastic deformation and oxidation are expected to be more prominent in Si than in $\mathrm{SiC}$.

Figure 7 shows representative SEM micrographs of the wear track area for all the samples studied. In the case of Hexoloy, significant scoring was observed which can be attributed to abrasive wear from pulled SiC grains. This effect was also observed in bioSiC although its contribution to total wear appeared to be smaller. Significant removal of Si can be seen in all bioSiC samples at all loads: it is very evident in the included micrograph of maple-derived bioSiC, where the surface of the elongated, Si-filled channels is recessed with respect to the $\mathrm{SiC}$ phase. A similar observation can be made in the case of black walnut derived bioSiC where additionally wear debris collected inside the hollow channels as a non-electrically conductive phase (seen in bright contrast in the SEM micrographs). The collection of wear debris inside the hollow channels in bioSiC could explain the absence of extensive scoring in the wear tracks, in contrast with Hexoloy. These structured surfaces, either due to the presence of channels in the original microstructure or due to recession of the Si phase due to differential wear, could have an impact in lubricated wear behavior [36] [37]. 
Wear debris was carefully collected with carbon adhesive tape for analysis using EDS in the SEM (data not shown); debris in the wear track contained Si and 0 in an atomic ratio of $\sim 1: 3$. EDS analysis were performed in the $\mathrm{Si}_{3} \mathrm{~N}_{4}$ ball as well, where the presence of oxygen was confirmed both in the contact area as well as on surfaces not directly in contact with the disk during the tests. These results suggest that tribo-oxidation of both the ball and the disk contributed to total wear, as previously suggested in other $\mathrm{SiC}$ and $\mathrm{Si}_{3} \mathrm{~N}_{4}$ materials. In studies of unlubricated SiC against SiC wear at room temperature and humidity using different geometries, Andersson and Blomberg [33] observed both passive (involving $\mathrm{SiO}_{2}$ formation) and active (through formation of SiO) oxidation, while Cranmer [35] measured contact temperatures as high as $400{ }^{\circ} \mathrm{C}$ for ring on ring tests with relative sliding speeds of $\sim 3 \mathrm{~m} \mathrm{~s}^{-1}$.

To further confirm the presence of an oxide film in the wear tracks, the fluorescence images and spectra from the wear track regions were collected with an epifluorescence optical microscope using $405 \mathrm{~nm}$ near UV light. Emission at a peak wavelength of $\sim 450 \mathrm{~nm}$ was detected from the wear tracks of all the samples studied. Figure 8.A (color online) shows representative optical fluorescence images as well as SEM images of the corresponding regions, where brighter contrast in the fluorescence micrographs corresponds to higher emission intensity. Figure 8.B. shows the collected spectra from maple and mahogany-derived bioSiC, as well as Hexoloy and a silicon single crystal wafer tested under the same conditions as the rest of the samples. Spectra are normalized to the same scale and shifted for ease of comparison. Tribo-oxidation and formation of an oxide layer in SiC ceramics has been documented [33-35], however no data exists in the literature for oxidative wear of silicon. In the case of $\mathrm{SiC}$, temperatures in excess of $400^{\circ} \mathrm{C}$ were determined at sliding speeds $\sim 2 \mathrm{~m} \mathrm{~s}^{-1}$ at the center of disk samples, midthickness [35].

\section{Conclusions}

We have studied the hardness and wear resistance of biomorphic SiC ceramics derived from different wood precursors. Knoop hardness is shown to correlate with increasing SiC content as would be expected from a rule of mixtures relationship. The lower hardness of residual Si results in this phase to wear at a higher rate and thus create a recessed microstructure. Abrasion from the $\mathrm{SiC}$ debris and ploughing appear to be the main overall wear mechanism. Tribo-oxidation was confirmed by means of fluorescence spectroscopy and contributes to total wear. 


\section{Acknowledgements}

SEM and XRD observations and tribological tests were performed at CITIUS (Universidad de Sevilla). Profile meter measurements were carried out at ICMS (CSIC) with the help and advice of Dr. J. C. Sánchez-López. Prof. F. Gutierrez-Mora assisted us with the use of the confocal microscope. M C. Vera gratefully acknowledges funding from the Spanish Ministerio de Educación, Cultura y Deporte under a FPU grant.

\section{Tables}

Table 1. Estimated volume fractions of $\mathrm{C}, \mathrm{SiC}$ and $\mathrm{Si}$ for all four types of samples studied, as well as average geometric density and surface roughness. Quoted errors represent one standard deviation. In Black Walnut derived bioSiC roughness could not be measured due to the presence of hollow channels.

\begin{tabular}{l|ccccc} 
Precursor & C+Porosity (\%) & SiC (\%) & Si (\%) & $\begin{array}{l}\rho\left(\mathrm{g} \mathrm{cm}^{-}\right. \\
3)\end{array}$ & $\mathrm{Ra}(\mu \mathrm{m})$ \\
\hline Black Walnut & $33 \pm 4$ & $42 \pm 3$ & $25 \pm 3$ & 2.3 & - \\
Mahogany & $2 \pm 2$ & $53 \pm 5$ & $45 \pm 6$ & 2.5 & 0.042 \\
Maple & $0.4 \pm 0.4$ & $56 \pm 4$ & $43 \pm 4$ & 2.8 & 0.044 \\
Sugar Pine & $1 \pm 1$ & $27 \pm 6$ & $72 \pm 7$ & 2.6 & 0.077 \\
\hline
\end{tabular}

\section{List of Figures}

Figure 1. SEM micrographs of axial sections of the bioSiC materials obtained from the four types of precursors used. Dark contrast is due to residual carbon and / or pores. Light contrast is due to residual silicon, and intermediate contrast is due to silicon carbide.

Figure 2. Measured Knoop hardness as a function of SiC volume fraction, determined from SEM measurements. The Hexoloy material does not have a $\mathrm{SiC}$ volume fraction of $100 \%$ due to the presence of residual porosity, see text for details. Error bars correspond to three standard deviations.

Figure 3. Friction coefficient of the different types of bioSiC, Si and Hexoloy materials against a $\mathrm{Si}_{3} \mathrm{~N}_{4}$ ball versus sliding distance. Sliding speed was $100 \mathrm{~mm} / \mathrm{s}$, while load was $2 \mathrm{~N}$ (top) and $5 \mathrm{~N}$ (bottom). 
Figure 4. Mean friction coefficient of the tested materials, averaged over the last $200 \mathrm{~m}$ of sliding, as a function of $\mathrm{SiC}$ volume fraction.

Figure 5. Measured wear rates for the $\mathrm{Si}_{3} \mathrm{~N}_{4}$ ball (top) and the disk material (bottom), for the two applied loads. In the case of the disk wear rate, two different measuring techniques were employed. Wear rate of the black walnut-derived bioSiC could not be measured due to the presence of large hollow channels perpendicular to the disk surface.

Figure 6. Wear rate of the different materials studied as a function of $\mathrm{SiC}$ volume fraction, determined from SEM measurements. The Hexoloy material does not have a SiC volume fraction of $100 \%$ due to the presence of residual porosity, see text for details. Error bars correspond to one standard deviation.

Figure 7. Representative SEM micrographs of the wear tracks for bioSiC obtained from different precursors as well as Hexoloy.

Figure 8. A) SEM micrographs along with Optical Fluorescence Microscopy of representative wear tracks in maple and mahogany derived bioSiC. B) Photoluminescence spectra obtained using a near-UV laser at $405 \mathrm{~nm}$ wavelength from the wear scar in bioSiC derived from mahogany and maple, as well as Hexoloy. The luminescence spectra from the wear track of a Si single crystal wafer tested under similar conditions as the $\mathrm{SiC}$ material is included for comparison. Spectra is normalized and shifted vertically for ease of comparison.

\section{References}

[1] Greil P, Lifka T, Kaindl A. Biomorphic cellular silicon carbide ceramics from wood: I. Processing and microstructure. J Eur Ceram Soc. 1998;18:1961-73.

[2] Sieber H, Hoffmann C, Kaindl A, Greil P. Biomorphic Cellular Ceramics. Adv Eng Mater. 2000;2:105-9.

[3] Greil P. Biomorphous ceramics from lignocellulosics. J Eur Ceram Soc. 2001;21:105-18.

[4] de Arellano-Lopez AR, Martinez-Fernandez J, Gonzalez P, Dominguez C, Fernandez-Quero V, Singh M. Biomorphic SiC: A new engineering ceramic material. Int J Appl Ceram Tec. 2004;1:5667.

[5] Varela-Feria FM, Ramirez-Rico J, de Arellano-Lopez AR, Martinez-Fernandez J, Singh M. Reaction-formation mechanisms and microstructure evolution of biomorphic SiC. J Mater Sci. 2008;43:933-41. 
[6] Torres-Raya C, Hernandez-Maldonado D, Ramirez-Rico J, Garcia-Ganan C, de Arellano-Lopez AR, Martinez-Fernandez J. Fabrication, chemical etching, and compressive strength of porous biomimetic SiC for medical implants. J Mater Res. 2008;23:3247-54.

[7] Gonzalez P, Serra J, Liste S, Chiussi S, Leon B, Perez-Amor M, et al. New biomorphic SiC ceramics coated with bioactive glass for biomedical applications. Biomaterials. 2003;24:482732.

[8] Gonzalez P, Borrajo JP, Serra J, Liste S, Chiussi S, Leon B, et al. Extensive studies on biomorphic SiC ceramics properties for medical applications. Bioceramics, Vol 16. 2004;2542:1029-32.

[9] Borrajo JP, Serra J, Liste S, Gonzalez R, Chiussi S, Leon B, et al. Pulsed laser deposition of hydroxylapatite thin films on biomorphic silicon carbide ceramics. Appl Surf Sci. 2005;248:355-9.

[10] de Carlos A, Borrajo JP, Serra J, Gonzalez P, Leon B. Behaviour of MG-63 osteoblast-like cells on wood-based biomorphic SiC ceramics coated with bioactive glass. J Mater Sci-Mater M. 2006;17:523-9.

[11] Borrajo JP, Gonzalez P, Serra J, Liste S, Chiussi S, Leon B, et al. Cytotoxicity study of biomorphic SiC ceramics coated with bioactive glass. Bol Soc Esp Ceram V. 2006;45:109-14. [12] Borrajo JP, Gonzalez P, Serra J, Liste S, Chiussi S, Leon B, et al. Biomorphic silicon carbide ceramics coated with bioactive glass for medical applications. Mater Sci Forum. 2006;514516:970-4.

[13] Gonzalez P, Borrajo JP, Serra J, Chiussi S, Leon B, Martinez-Fernandez J, et al. A new generation of bio-derived ceramic materials for medical applications. J Biomed Mater Res A. 2009;88A:807-13.

[14] Lelli M, Foltran I, Foresti E, Martinez-Fernandez J, Torres-Raya C, Varela-Feria FM, et al. Biomorphic Silicon Carbide Coated with an Electrodeposition of Nanostructured Hydroxyapatite/Collagen as Biomimetic Bone Filler and Scaffold. Adv Eng Mater. 2010;12:B348-B55.

[15] Will J, Hoppe A, Muller FA, Raya CT, Fernandez JM, Greil P. Bioactivation of biomorphous silicon carbide bone implants. Acta Biomater. 2010;6:4488-94.

[16] Filardo G, Kon E, Tampieri A, Cabezas-Rodriguez R, Di Martino A, Fini M, et al. New BioCeramization Processes Applied to Vegetable Hierarchical Structures for Bone Regeneration: An Experimental Model in Sheep. Tissue Eng Pt A. 2014;20:763-73. 
[17] Presas M, Pastor JY, Llorca J, de Arellano-Lopez AR, Martinez-Fernandez J, Sepulveda RE. Mechanical behavior of biomorphic Si/SiC porous composites. Scripta Mater. 2005;53:1175-80. [18] Presas M, Pastor JY, Llorca J, Lopez ARA, Fernandez JM, Sepulveda R. Microstructure and fracture properties of biomorphic SiC. Int J Refract Met H. 2006;24:49-54.

[19] de Arellano-Lopez AR, Martinez Fernandez J, Varela Feria FM, Sepulveda RE, Lopez Robledo MJ, Llorca J, et al. Processing, microstructure and mechanical behavior of SiC-based ceramics VIA naturally derived scaffolds. Ceramics Engineering and Science Proceedings. 2006;27:635-50.

[20] Fernandez JM, Munoz A, Lopez ARD, Feria FMV, Dominguez-Rodriguez A, Singh M. Microstructure-mechanical properties correlation in siliconized silicon carbide ceramics. Acta Mater. 2003;51:3259-75.

[21] Kaul VS, Faber KT. Nanoindentation analysis of the elastic properties of porous SiC derived from wood. Scripta Mater. 2008;58:886-9.

[22] Kaul VS, Faber KT, Sepulveda R, Lopez ARD, Martinez-Fernandez J. Precursor selection and its role in the mechanical properties of porous SiC derived from wood. Mat Sci Eng aStruct. 2006;428:225-32.

[23] Gutierrez-Mora F, Goretta KC, Varela-Feria FM, Lopez ARA, Fernandez JM. Indentation hardness of biomorphic SiC. Int J Refract Met H. 2005;23:369-74.

[24] de Arellano-Lopez AR, Martinez-Fernandez J, Varela-Feria FM, Orlova TS, Goretta KC, Gutierrez-Mora F, et al. Erosion and strength degradation of biomorphic SiC. J Eur Ceram Soc. 2004;24:861-70.

[25] Amirthan G, Udayakumar A, Prasad VVB, Balasubramanian M. Solid particle erosion studies on biomorphic Si/SiC ceramic composites. Wear. 2010;268:145-52.

[26] Varela-Feria FM, Martinez-Fernandez J, de Arellano-Lopez AR, Singh M. Low density biomorphic silicon carbide: microstructure and mechanical properties. J Eur Ceram Soc. 2002;22:2719-25.

[27] Varela-Feria FM, Lopez-Robledo MJ, Martinez-Fernandez J, de Arellano-Lopez AR, Singh M. Precursor selection for property optimization in biomorphic SiC ceramics. Ceramics Engineering and Science Proceedings. 2002;23:681-85.

[28] Singh M, Martinez-Fernandez J, de Arellano-Lopez AR. Environmentally conscious ceramics (ecoceramics) from natural wood precursors. Curr Opin Solid St M. 2003;7:247-54. 
[29] Varela-Feria FM, Ramirez-Rico J, Martinez-Fernandez J, de Arellano-Lopez AR, Singh M. Infiltration and reaction-formation mechanism and microstructural evolution of biomorphic SiC fabricated by Si-melt infiltration. Ceramic Transactions. 2006;177:93-101.

[30] Singh M, Yee BM. Reactive processing of environmentally conscious, biomorphic ceramics from natural wood precursors. J Eur Ceram Soc. 2004;24:209-17.

[31] Hayafuji Y, Kawado S, Ishii Z. Knoop Hardness of Phosphorus-Diffused Silicon SingleCrystals. Jpn J Appl Phys. 1972;11:1389-\&.

[32] Takadoum J, Zsiga Z, Roquescarmes C. Wear Mechanism of Silicon-Carbide - New Observations. Wear. 1994;174:239-42.

[33] Andersson P, Blomberg A. Instability in the Tribochemical Wear of Silicon-Carbide in Unlubricated Sliding Contacts. Wear. 1994;174:1-7.

[34] Dong X, Jahanmir S, Ives LK. Wear transition diagram for silicon carbide. Tribol Int. 1995;28:559-72.

[35] Cranmer DC. Friction and Wear Properties of Monolithic Silicon-Based Ceramics. J Mater Sci. 1985;20:2029-37.

[36] Erdemir A. Review of engineered tribological interfaces for improved boundary lubrication. Tribol Int. 2005;38:249-56.

[37] Wang XL, Adachi K, Otsuka K, Kato K. Optimization of the surface texture for silicon carbide sliding in water. Appl Surf Sci. 2006;253:1282-6. 
Figure 1

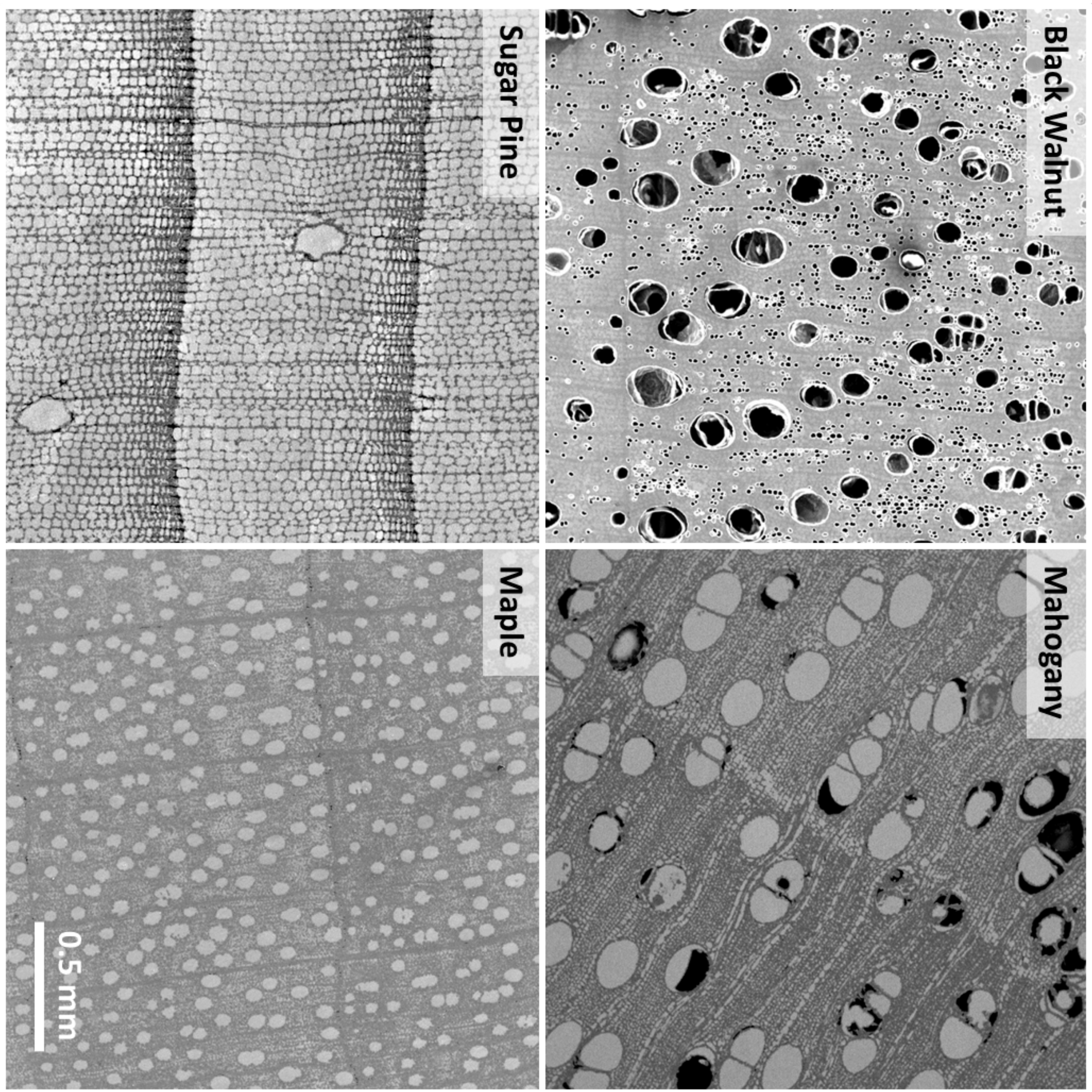


Figure 2
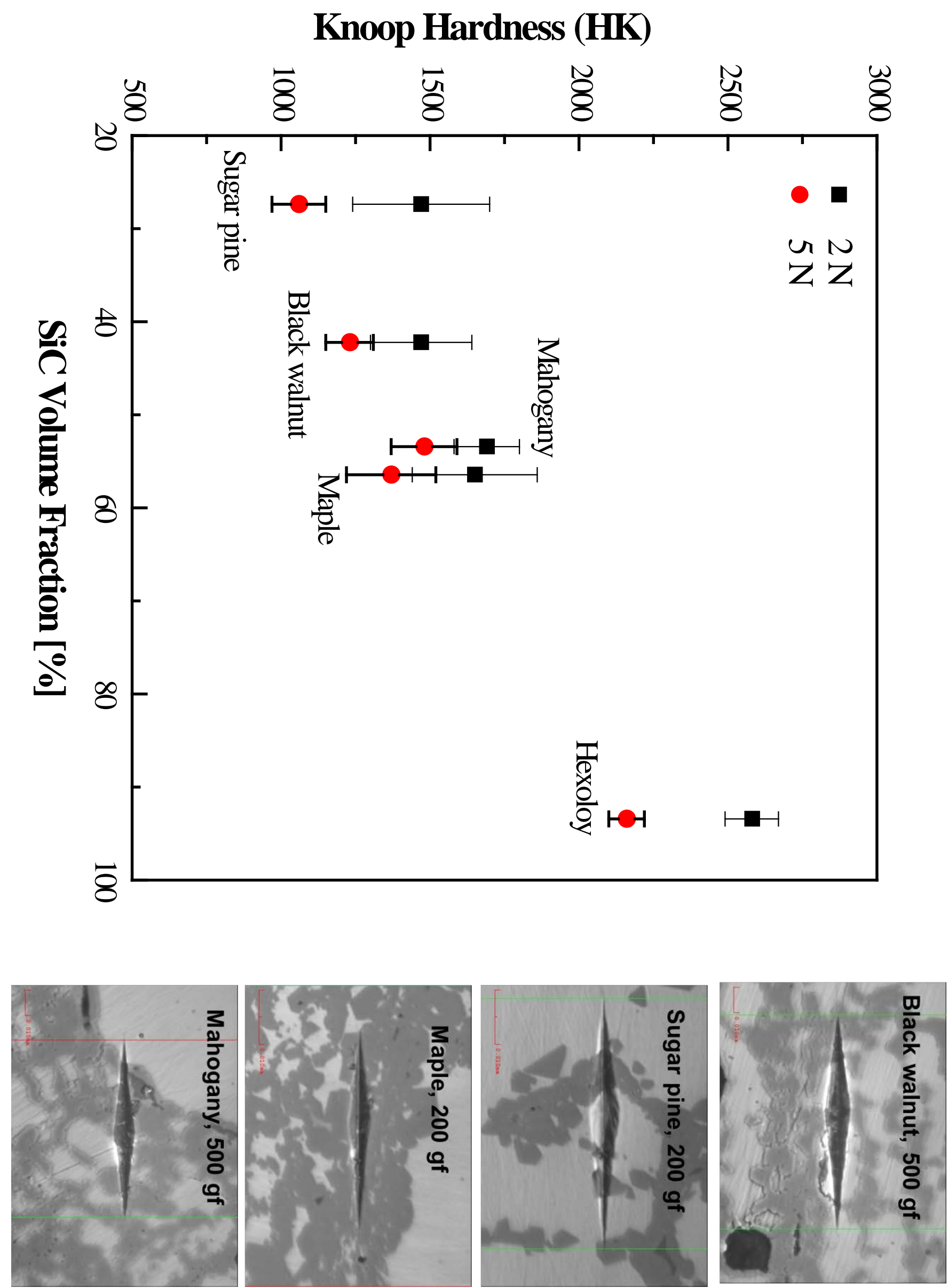
Friction coefficient

Friction coefficient
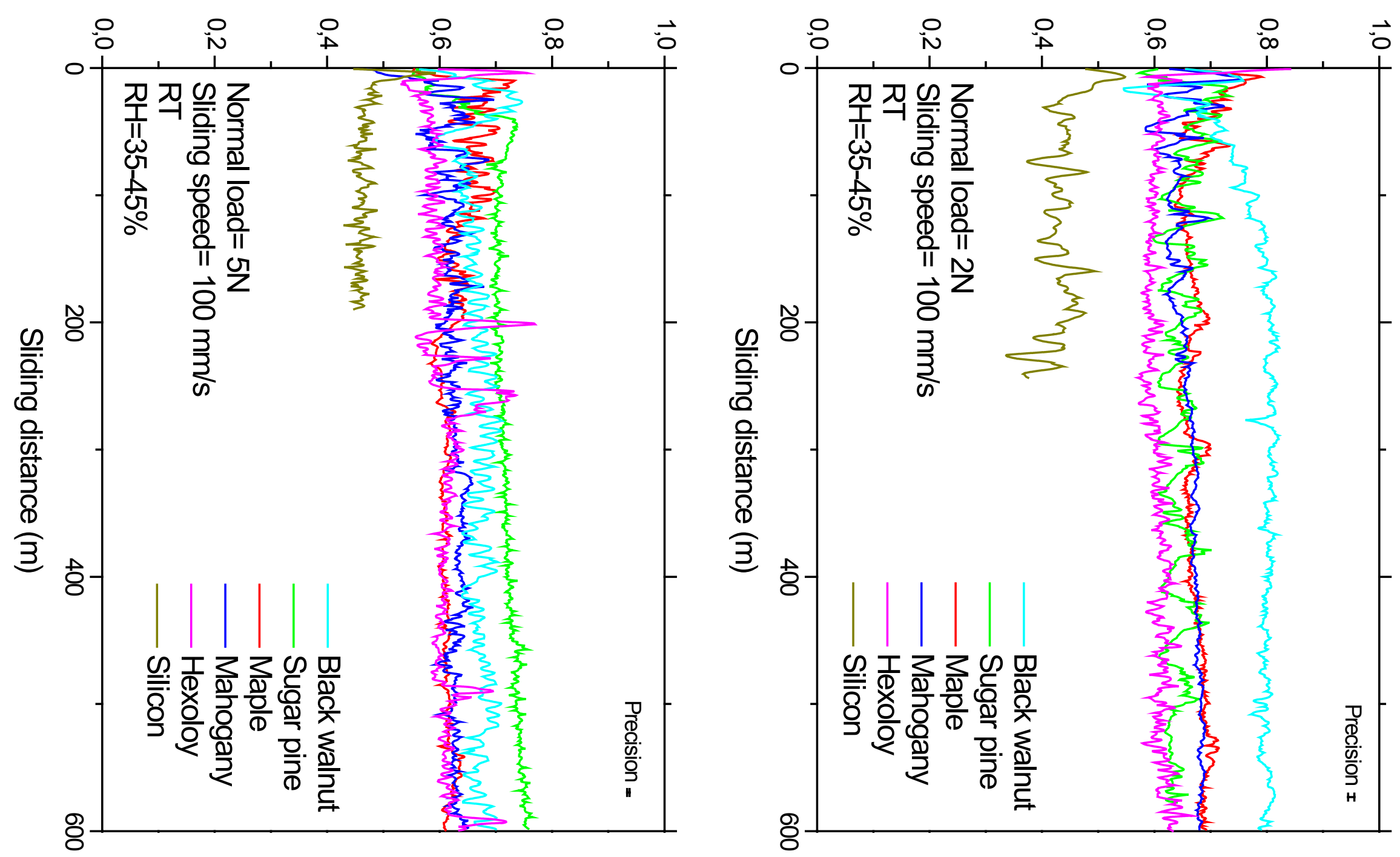
Figure 4

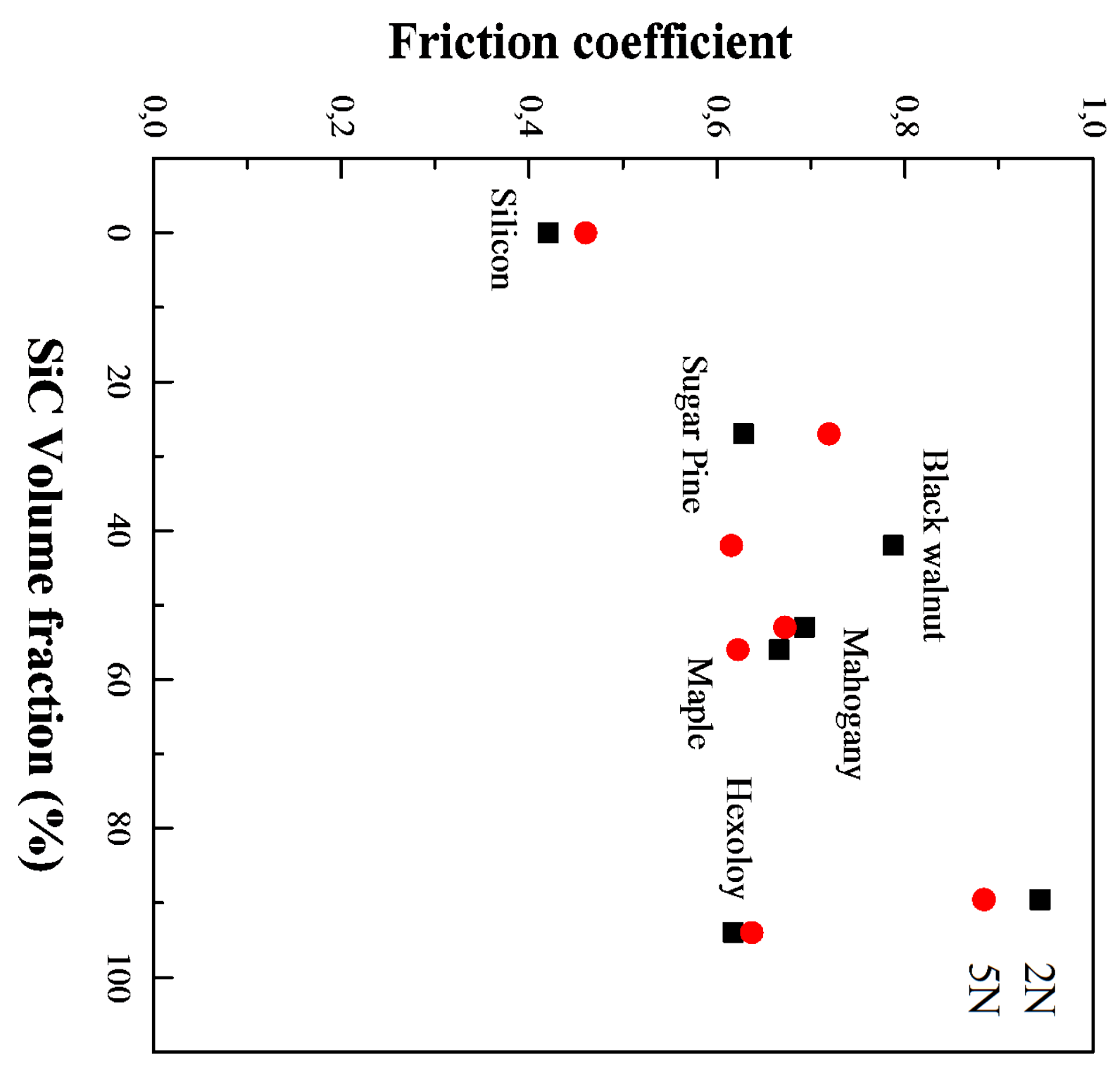


Figure 5
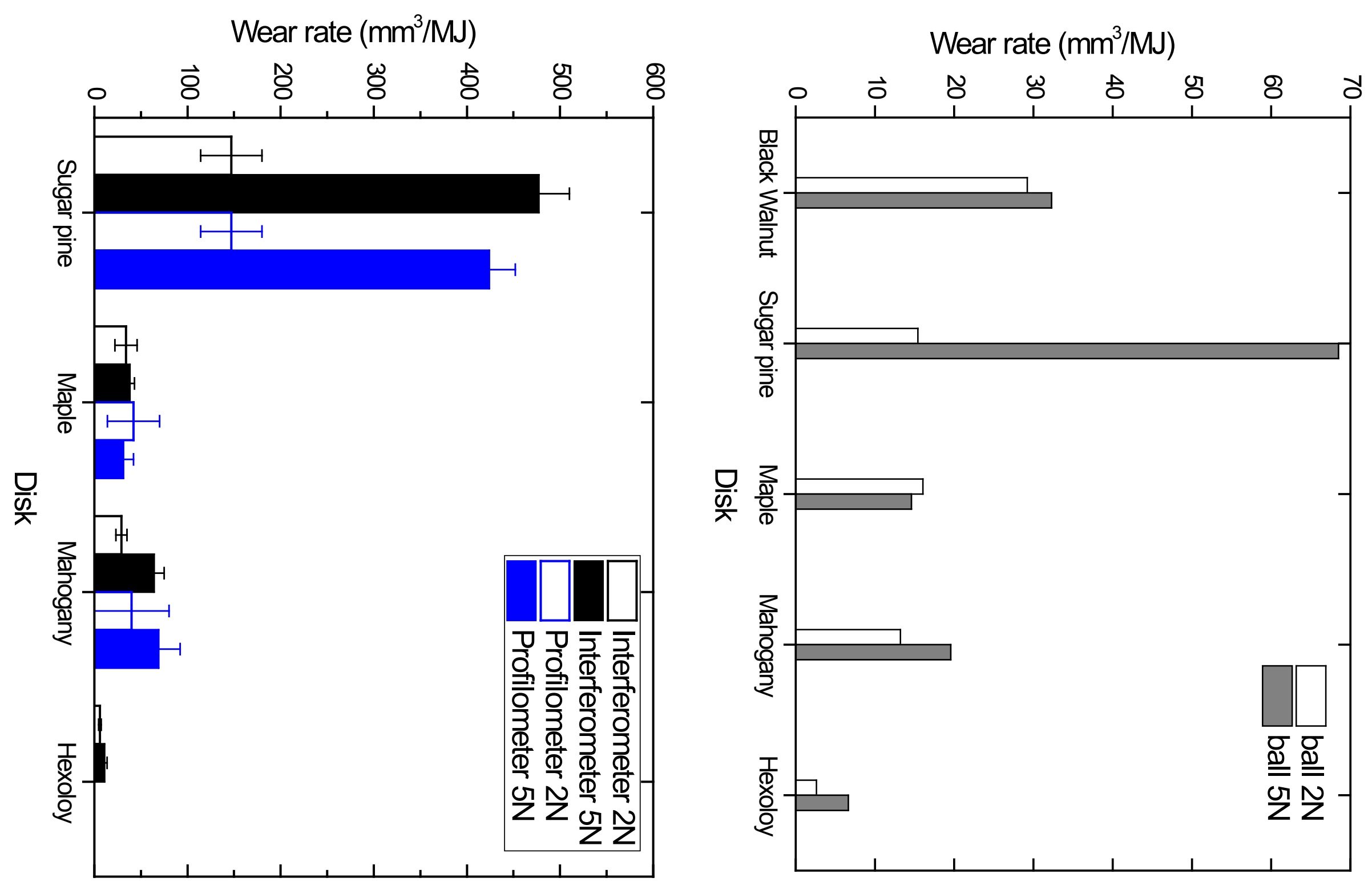
Figure 6

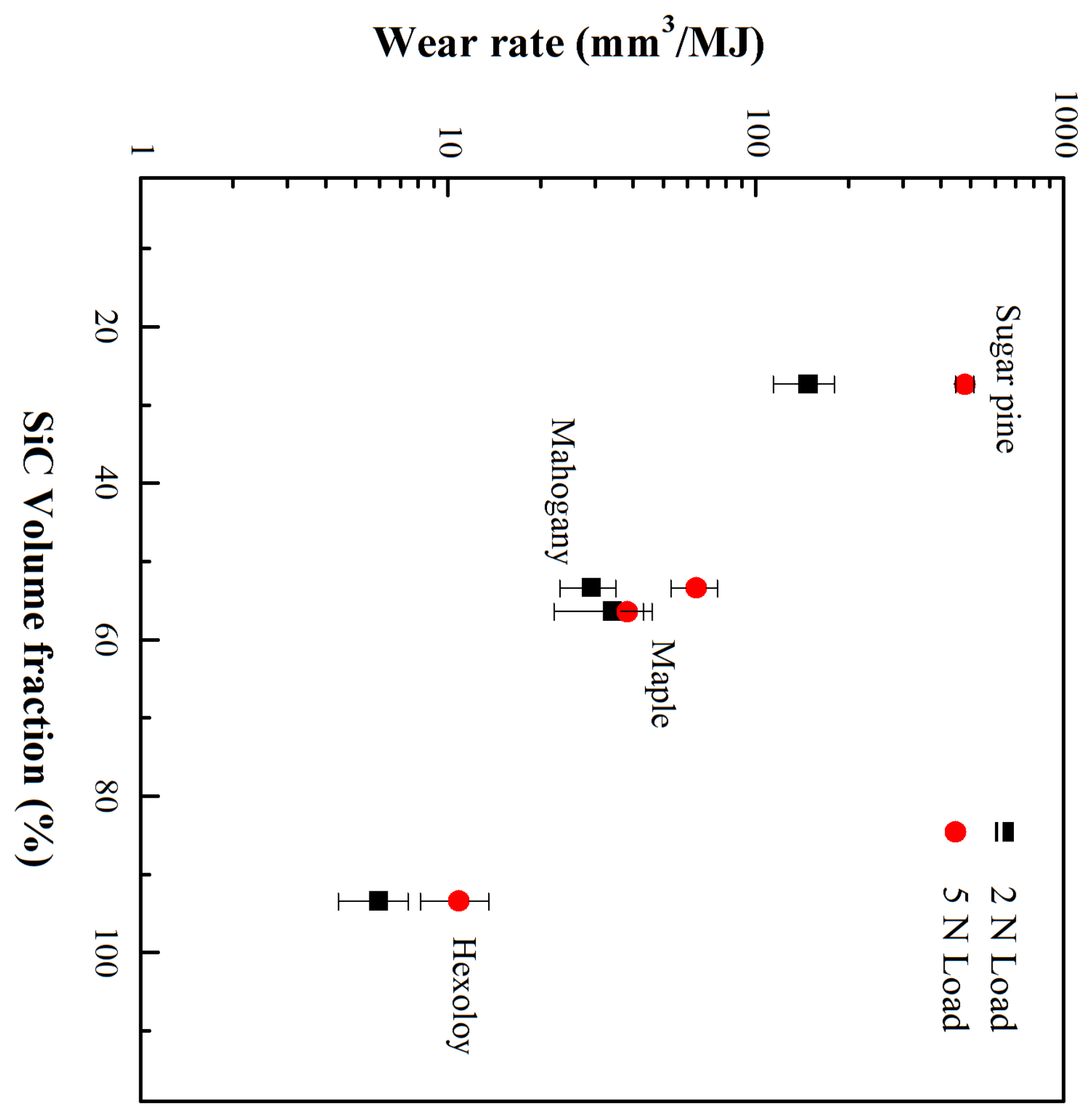


Figure 7
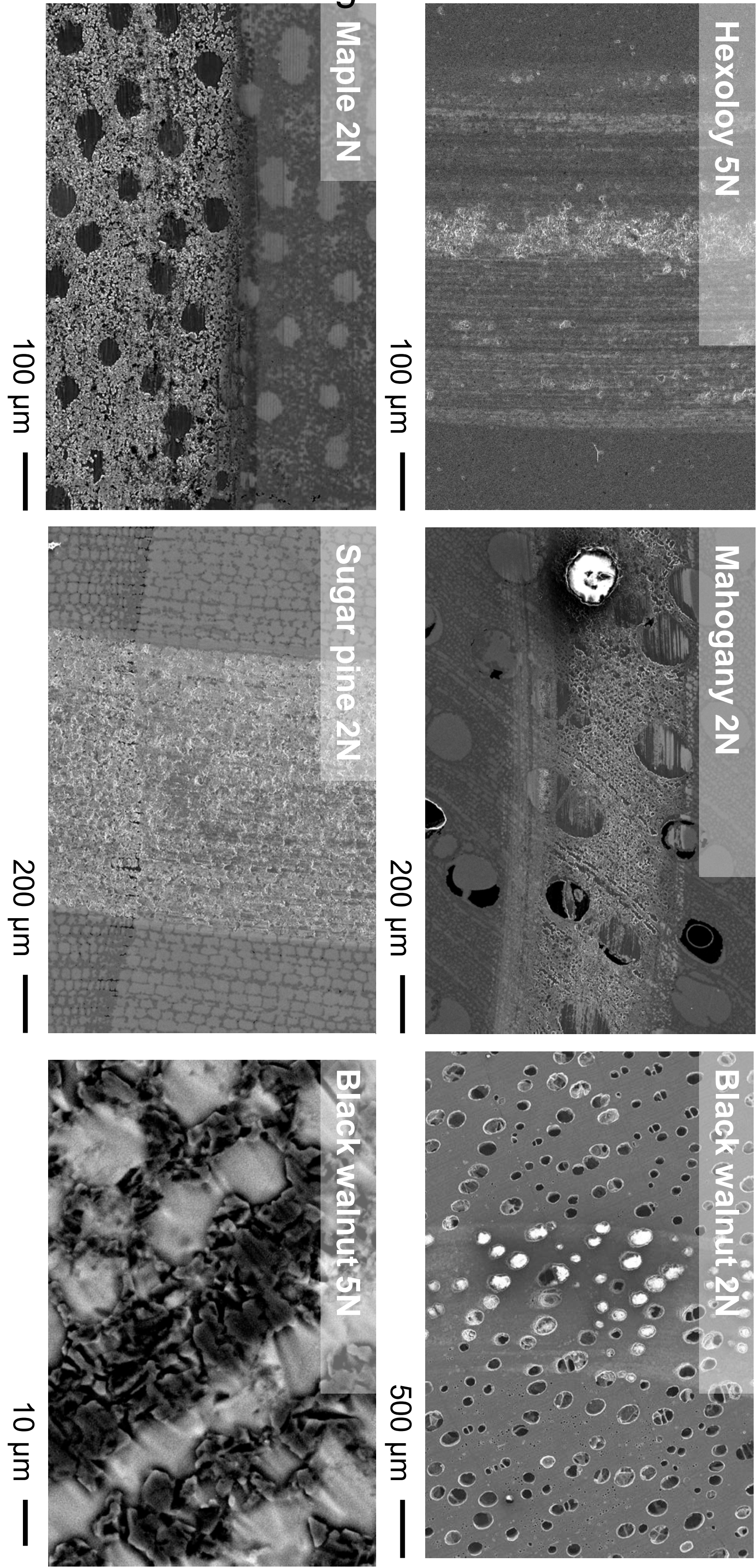
Figure 8
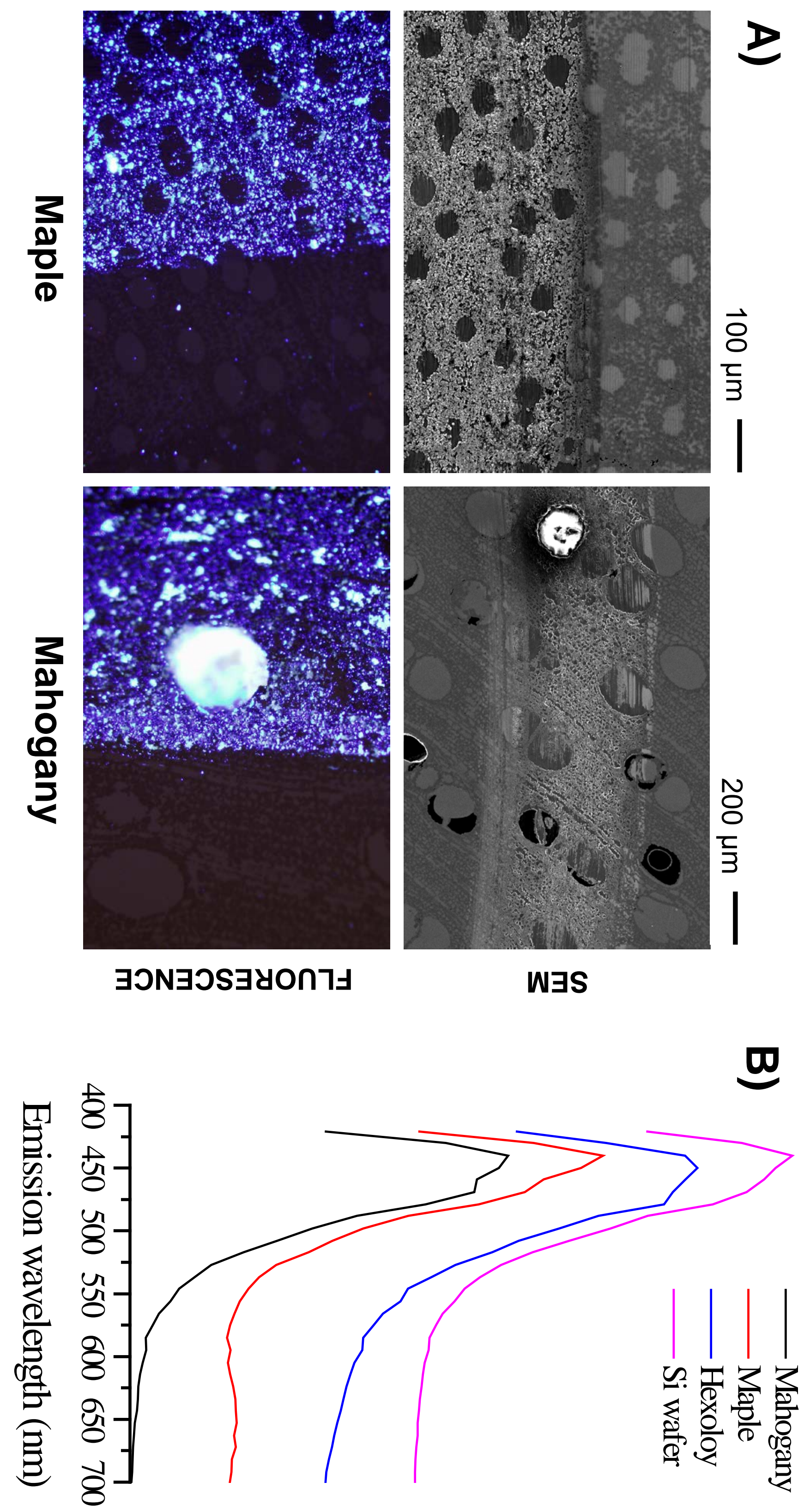